\title{
Gerontology
}

\section{Cognitive Predictors of Everyday Problem Solving across the Lifespan}

\author{
Xi Chen ${ }^{\mathrm{a}}$ Christopher Hertzog ${ }^{\mathrm{b}}$ Denise C. Park ${ }^{\mathrm{a}}$ \\ ${ }^{a}$ Center for Vital Longevity, School of Behavioral and Brain Sciences, University of Texas at Dallas, Dallas, TX, and

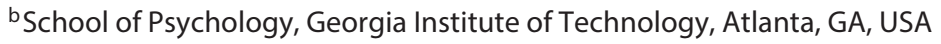

\section{Keywords}

Age-related changes · Cognition · Intelligence · Everyday problem solving

\begin{abstract}
Background: An important aspect of successful aging is maintaining the ability to solve everyday problems encountered in daily life. The limited evidence today suggests that everyday problem solving ability increases from young adulthood to middle age, but decreases in older age. Objectives: The present study examined age differences in the relative contributions of fluid and crystallized abilities to solving problems on the Everyday Problems Test (EPT). We hypothesized that due to diminishing fluid resources available with advanced age, crystallized knowledge would become increasingly important in predicting everyday problem solving with greater age. Method: Two hundred and twenty-one healthy adults from the Dallas Lifespan Brain Study, aged 24-93 years, completed a cognitive battery that included measures of fluid ability (i.e., processing speed, working memory, inductive reasoning) and crystallized ability (i.e., multiple measures of vocabulary). These measures were used to predict performance on EPT. Results: Everyday problem solving showed an increase in performance from young
\end{abstract}

\section{KARGER}

(C) 2017 S. Karger AG, Basel

E-Mail karger@karger.com

www.karger.com/ger to early middle age, with performance beginning to decrease at about age of 50 years. As hypothesized, fluid ability was the primary predictor of performance on everyday problem solving for young adults, but with increasing age, crystallized ability became the dominant predictor. Conclusion: This study provides evidence that everyday problem solving ability differs with age, and, more importantly, that the processes underlying it differ with age as well. The findings indicate that older adults increasingly rely on knowledge to support everyday problem solving, whereas young adults rely almost exclusively on fluid intelligence.

(c) 2017 S. Karger AG, Basel

\section{Cognitive Predictors of Everyday Problem Solving across the Lifespan}

An important aspect of successful aging is maintaining the ability to solve everyday problems encountered in daily life. Instrumental Activities of Daily Living (IADLs) represent one important domain of these problems. IADLs are complex behaviors required for independent management of one's life, including adherence to complex medical regimens, ability to use increasingly complex communication devices, and management of finan- 
cial resources [1]. Other everyday problems involve situations where a conflict is present or a goal cannot be reached without some inferential reasoning [2]. Crosssectional data show that the practical ability to solve everyday problems increases from young adulthood until middle age [3-5], but that older age is characterized by diminishing performance [4-7].

One reason for peak performance during middle adulthood in everyday problem solving may be that middle-aged adults have the ideal balance of fluid and crystallized resources needed for everyday problem solving. Crystallized ability represents accumulated experience and knowledge of the world, and is typically measured by vocabulary and general knowledge. It does not decline, and may even grow, well into late adulthood $[8,9]$. In contrast, fluid ability - the ability to abstract and perform efficient mental operations - shows consistent age-related decline beginning in the 20s [9], but nevertheless, performance is still relatively high in middle-aged adults [10]. Fluid ability is best measured by different types of inductive and deductive reasoning tasks, and is closely related to the construct of processing resources [11] as operationalized by working memory [12].

Previous studies have found fluid ability to be an important predictor of everyday problem solving in healthy older adults [6, 7, 13-17]. Gross et al. [15] found that although memory, reasoning, and processing speed were all significant predictors of everyday functioning and everyday problem solving, inductive reasoning (measured by Letter Series, Word Series, and Letter Sets tasks) independently accounted for the most variance in everyday functioning (measured by the Everyday Problems Test [EPT], the Observed Tasks of Daily Living [OTDL], and the Timed Instrumental Activities of Daily Living test). Willis et al. [18] also showed that older adults who underwent reasoning training showed less functional decline in IADLs than an untrained control group, indicating the importance of reasoning for everyday problem solving.

Everyday problem solving is also related to other aspects of fluid ability that decline with age, especially working memory and processing speed. Importantly, age-related decreases in working memory, using traditional measures that include Reading Span, Computation Span, and Operation Span tasks, have been strongly associated with lower performance on everyday problem solving tasks $[13,19]$. Age-related slowing in processing speed has also been associated with decreased everyday problem solving [7, 20]. Rebok et al. [21] reported evidence that older adults who had extensive training on process-

Cognitive Predictors of Everyday Problem Solving ing speed in the ACTIVE trial reported less difficulty in performing IADLs 10 years after training, suggesting that such an intervention confers protection in later life. In sum, there is little doubt that fluid ability plays an important role in everyday problem solving.

What is less certain is the role that crystallized ability and knowledge play in everyday problem solving. There have been a few studies that examined the joint contributions of both fluid ability and crystallized ability to everyday problem solving, and all suggest an important role of fluid ability $[6,13,14,16,20,22,23]$. However, the importance of crystallized ability in everyday problem solving seems to be different depending on the age range of the sample included in the study. Three studies in older adults all found that both fluid and crystallized ability played very important roles in everyday problem solving. Diehl et al. [14] used structural equation modeling and found that both fluid and crystallized abilities had significant paths to everyday problem solving, measured by OTDL. In addition, the effects of memory and speed on OTDL were mediated by crystallized ability, indexed by vocabulary. Burton et al. [20] used hierarchical regression and found that verbal ability, measured by verbal fluency and vocabulary tasks, predicted performance in EPT beyond the effect of fluid ability and demographic variables (e.g., age, education). Allaire and Marsiske [13] also found a relationship between vocabulary and some domains of everyday problem solving, measured by Everyday Cognition Battery. However, studies including middle-aged adults yielded somewhat different conclusions on the role of crystallized ability in the relation to everyday problem solving. Kimbler [6] studied healthy middle-aged and older adults (age 50-92 years) and found no relationship between performance in vocabulary and EPT. Thornton et al. [23] reported that, although in a sample of healthy adults and chronic disease patients, crystallized ability (measured by Educational Testing Service [ETS] vocabulary) mediated age effects on performance in EPT, the relationship was not significant when the analysis was limited only to healthy adults.

These findings suggest that there is a discrepancy in the role of crystallized ability in predicting everyday problem solving across the adulthood lifespan. A potential explanation is that there may be an age-related shift in the contribution of fluid versus crystallized abilities in solving everyday problems. This shift can only be detected by using a lifespan sample with a broader age range. We are aware of only 2 adult lifespan studies on the cognitive predictors of performance in everyday problem solving [5, $22]$. In both studies, the correlation of fluid and crystal-

Gerontology 2017;63:372-384

DOI: $10.1159 / 000459622$
373 


\section{Form: Order Blank for Sweeper Accessories}

\begin{tabular}{|c|c|c|c|c|c|}
\hline \multicolumn{6}{|c|}{$\begin{array}{l}\text { Pfier good in the United States only. } \\
\text { Allow } 4-6 \text { weeks for delivery. Prices subject to change. }\end{array}$} \\
\hline \multicolumn{2}{|c|}{ PRODUCT DESCRIPTION } & $\begin{array}{c}\text { PART. } \\
\text { NUMBER } \\
\end{array}$ & \begin{tabular}{|l|l|l} 
OTY. & $p$ \\
\end{tabular} & $\begin{array}{l}\text { PRICE } \\
\text { EACH } \\
\end{array}$ & $\begin{array}{c}\text { TOTAL } \\
\text { AMOUNT }\end{array}$ \\
\hline \multicolumn{2}{|l|}{ Filter Bag } & $720330-00$ & & 2.25 & \\
\hline \multicolumn{2}{|l|}{ Upholstery Brush } & $130632-00$ & & 2.75 & \\
\hline \multicolumn{2}{|l|}{ Crevice Tool } & $134862-01$ & & 2.75 & \\
\hline \multicolumn{6}{|c|}{ Dirt \& Dust Collector } \\
\hline \multicolumn{2}{|c|}{$\begin{array}{l}\text { Kit A SAVE } 12 \% \\
\text { 3-Filter Bags }\end{array}$} & $3-720330-00$ & & $\begin{array}{l}\text { Special } \\
5.95 \\
\end{array}$ & \\
\hline \multicolumn{2}{|c|}{$\begin{array}{l}\text { Kit B SAVE } 19 \% \\
\text { Cleaning Altachment Kit } \\
\text { 1- Crevice Tool } \\
\text { 1- Upholstery Brush } \\
\text { 3- Filter Bags }\end{array}$} & $\begin{array}{l}1-134862-01 \\
1-130632-00 \\
3-720330-00\end{array}$ & & $\begin{array}{l}\text { Special } \\
9.95\end{array}$ & \\
\hline \multirow{4}{*}{$\begin{array}{l}\text { For Your Convenience } \\
\text { and future Dustbuster Acces- } \\
\text { sory mail orders, we will for- } \\
\text { ward an additional order } \\
\text { form with delivery of any } \\
\text { purchases made. }\end{array}$} & \multicolumn{3}{|c|}{ SUBTOTAL } & \multicolumn{2}{|l|}{$\$$} \\
\hline & \multicolumn{3}{|c|}{$\begin{array}{l}\text { LOCAL SALES TAX } \\
\text { (Except ID, ME. NV, ND. SD.VT. WY) }\end{array}$} & $\$$ & 1.00 \\
\hline & \multicolumn{3}{|c|}{ SHIPPING/HANDLING } & \multicolumn{2}{|c|}{$\$ \quad 1.50$} \\
\hline & \multicolumn{3}{|c|}{ TOTAL AMOUNT } & \multicolumn{2}{|l|}{$\$$} \\
\hline
\end{tabular}

25. If you need several filter bags, what part number should you order to get a special price?
a. 720330-00
b. $130632-00$
c. 134862-01
d. $3-720330-00$

Fig. 1. Example questions of the Everyday Problems Test.

26. What would your total bill be if you lived in Idaho and ordered an upholstery brush?
a. $\$ 4.25$
b. $\$ 5.25$
c. $\$ 5.95$
d. $\$ 7.00$

lized cognitive predictors to everyday problem solving (practical problem solving in [5]) was significant. However, when the effects of age and education on everyday problem solving were controlled, neither predictor was significant [5], limiting the understanding of their respective contribution. Moreover, we were unable to find any studies that include young, middle-age and older adults that examined how age affects the contribution of cognitive predictors to everyday problem solving. Therefore, the present study focuses on 2 important and unresolved issues. First, what is the strength of the contributions of fluid and crystallized abilities to everyday problem solving? And second, do these contributions shift in importance as a function of age? 


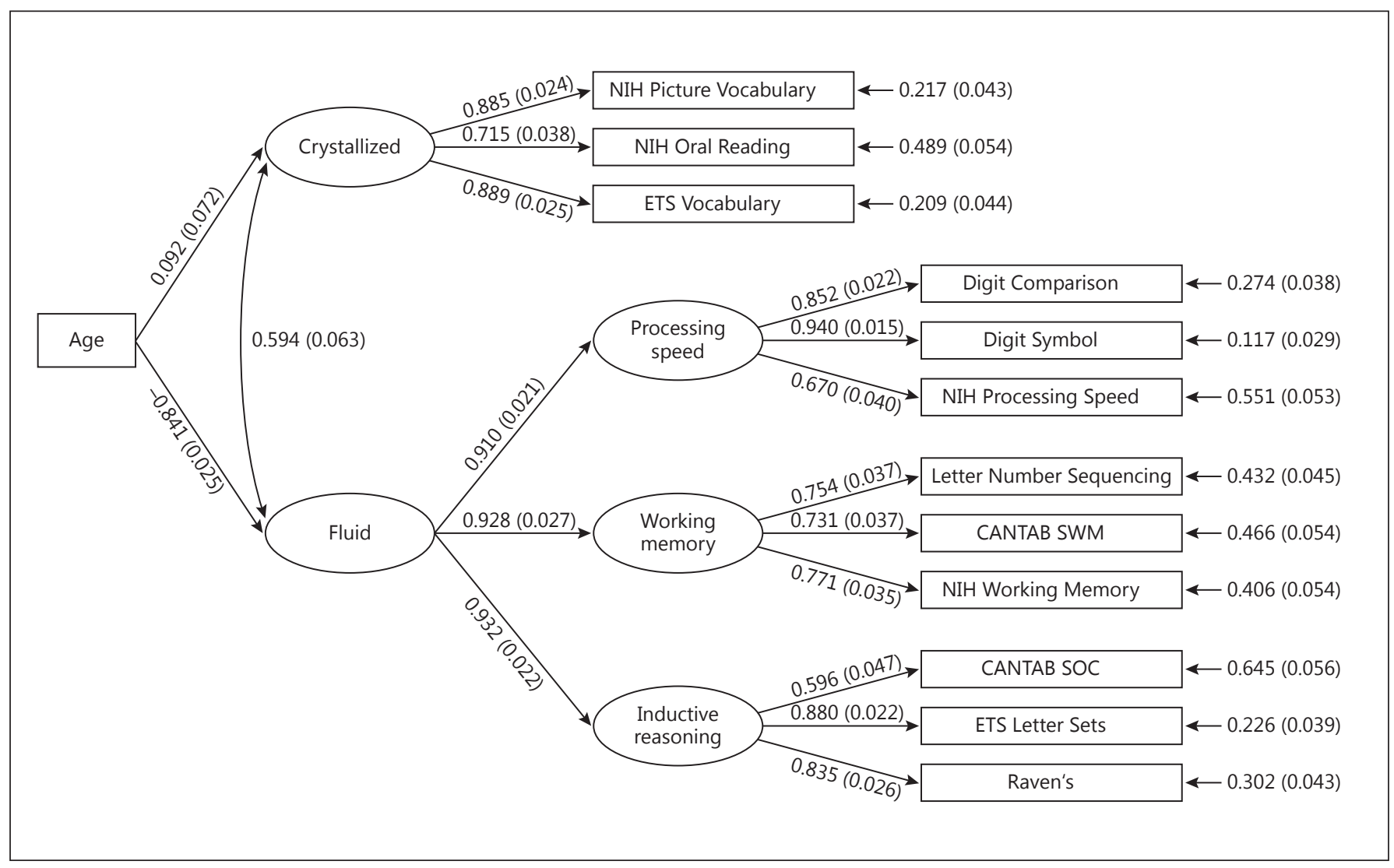

Fig. 2. Confirmatory factor analysis of cognitive tasks, after controlling for age. $\chi^{2}(60)=147.941, p<0.001$, $\mathrm{CFI}=0.953$, RMSEA $=0.081, \mathrm{SRMR}=0.076$.

Park [24] has argued that older adults maintain performance on many cognitive tasks by increasingly relying on knowledge and experience to compensate for declines in fluid abilities. Congruent with this perspective, Baltes et al. [25] also suggested that crystallized ability can compensate, to some extent, for age-related declines in processing efficiency with advanced age. In support of this theorizing, Hedden et al. [26] reported that performance on a verbal memory task was mediated by fluid abilities in young and middle-aged adults, but that older adults relied more on vocabulary (an index of crystallized ability) for optimal performance. In the present study, we determine whether such an age-related shift occurs for everyday problem solving in an adult lifespan sample. We predicted that young adults who are rich in cognitive resources such as speed, working memory and reasoning would rely on fluid processing for success; however, as age increased, crystallized ability would play an increasingly important role in everyday problem solving.

Cognitive Predictors of Everyday Problem Solving

\section{Materials and Method}

\section{Participants}

A total of 221 healthy adults from the Dallas Lifespan Brain Study (DLBS; 148 women, 73 men, age range: $24-93$ years, MiniMental Status Examination scores $\geq 26$, mean $=28.37$ ) were recruited locally from the community. All participants were righthanded with normal or corrected to normal vision. Participants with any of following conditions were excluded: history of major psychiatric or neurological disorder, history of prescription drug abuse/illegal drug use, and/or any head trauma. Participants were compensated USD 15.00 per hour for their participation. They completed two 2.5-h sessions that are described below.

\section{Materials}

Each participant completed a battery of cognitive tests as well as the EPT [27]. This comprehensive battery included both paperand-pencil and computerized tasks. The cognitive constructs assessed and the tasks associated with each construct included the following:

Processing speed was measured by Digit Comparison [28], WAIS-III Digit Symbol [29], and Pattern Comparison task taken from NIH Toolbox Cognition Battery (NIHTB-CB) [30]. 
Table 1. Demographic and descriptive data $(n=221)$

\begin{tabular}{lccc}
\hline & Young & Middle & Older \\
\hline Participants, $n$ & 72 & 73 & 76 \\
Age range, years & $24-49$ & $50-69$ & $70-93$ \\
Gender & & & \\
$\quad$ Female, $n$ & 49 & 49 & 50 \\
$\quad$ Male, $n$ & 23 & 24 & 26 \\
Years of education & $17.29(2.26)$ & $16.53(2.01)$ & $15.95(2.7)$ \\
MMSE score & $28.79(1.13)$ & $28.58(1.10)$ & $27.76(1.29)$ \\
\hline EPT Score & $37.36(3.98)$ & $37.23(3.08)$ & $31.24(6.68)$ \\
Fluid Ability & $0.67(0.46)$ & $0.12(0.49)$ & $-0.74(0.53)$ \\
Digit Comparison & $72.68(11.75)$ & $63.45(10.91)$ & $48.64(11.87)$ \\
Digit Symbol & $65.13(9.65)$ & $55.71(10.42)$ & $39.47(10.93)$ \\
NIH Processing Speed & $103.61(12.44)$ & $95.15(9.11)$ & $85.91(8.94)$ \\
Letter Number Sequencing & $13.39(2.74)$ & $11.95(2.69)$ & $9.42(2.68)$ \\
SWM Total Errors & $10.96(15.89)$ & $26.38(19.21)$ & $42.79(20.14)$ \\
NIH Working Memory & $112.89(10.79)$ & $106.72(10.45)$ & $95.17(10.97)$ \\
SOC Problems Solved & $10.03(1.84)$ & $8.93(1.92)$ & $7.74(1.79)$ \\
ETS Letter Sets & $22.41(4.67)$ & $19.94(4.56)$ & $12.88(5.71)$ \\
Raven's Progressive Matrices & $21.75(1.87)$ & $20.51(2.60)$ & $16.71(4.01)$ \\
Crystallized Ability & $-0.13(0.85)$ & $0.16(0.76)$ & $-0.04(1.02)$ \\
NIH Picture Vocabulary & $114.78(8.78)$ & $119.12(8.06)$ & $116.15(9.48)$ \\
NIH Oral Reading & $112.65(4.52)$ & $112.63(4.00)$ & $110.67(6.35)$ \\
ETS Vocabulary & $17.80(6.54)$ & $20.78(6.07)$ & $21.17(7.52)$ \\
\hline
\end{tabular}

Data are presented as mean (SD), or as stated.

Working memory was measured by the Spatial Working Memory (SWM) task of Cambridge Neuropsychological Test Automated Battery (CANTAB) [31], WAIS-III Letter-Number Sequencing [29], and NIHTB-CB List Sorting [30].

Inductive reasoning was measured by ETS Letter Sets [32], Raven's Progressive Matrices [33], and Stockings of Cambridge (SOC) of CANTAB [31].

Crystallized ability was measured by NIHTB-CB Picture Vocabulary [30], NIHTB-CB Oral Reading Recognition [30], and the ETS Advanced Vocabulary Scale [32]. Although the ETS Vocabulary task was timed, we made sure that no participants failed to complete the task because of the time limit, so the performance on this task was not affected by their speed.

Everyday problem solving ability was measured by EPT [27]. It is a paper-pencil task that has 42 questions, which assesses the ability to solve tasks that are important to live independently in our society. The EPT is comprised of 7 scales that include problems from the domains of Health/Medications, Meal Preparation/Nutrition, Phone Usage, Consumer/Shopping, Financial Management, Household Management, and Transportation. For each of these 7 scales, participants are presented with 3 sample stimuli (e.g., prescription drug label, bus schedule, catalog order form) and 2 questions about each stimulus. Figure 1 is an example of one EPT stimulus with 2 questions based on the stimulus. The performance on this task is measured as the total number of correct answers to the 42 questions. Compared to other neuropsychological tasks that assessed traditional problem solving ability, EPT was designed to be a better indicator of problem solving performance in real life. Schmitter-Edgecombe et al. [34] found that EPT was strongly associated with directly observed everyday functioning performance in real world, and therefore considered to be a valid and useful measure for assessing everyday functioning in cognitively healthy older population.

Data Analyses

Altogether, there were 13 tasks subjected to analyses: 3 measures each for processing speed, working memory, inductive reasoning, crystallized ability, and a single measure of everyday problem solving. We created standard scores for the 12 cognitive measures that were used for further analyses. A confirmatory factor analysis validated the expected factor structure of cognitive measures $\left(\chi^{2}(60)=147.941, p<0.001, \mathrm{CFI}=0.953\right.$, $\mathrm{RMSEA}=0.081$, SRMR $=0.076$; Fig. 2$)$. The standardized scores for each crystallized and fluid test were averaged to produce composite crystallized and fluid scores in a standard score (z-score) metric in the aggregate cross-sectional sample.

To test the hypothesis that crystallized intelligence would be a more potent predictor of everyday problem solving for older adults, relative to earlier ages, we conducted a hierarchical moderated regression analysis with age, fluid ability, and crystallized ability as predictors using product variables to capture interactions. Prior to evaluating the interaction effects, we introduced quadratic age effects to test for possible curvilinearity in the relation of age and the variables to the EPT score. This approach was taken be- 
cause curvilinear age relations were expected in abilities [35] and everyday problem solving performance, and because methodological studies have shown that failing to account for curvilinear relations of predictors to dependent variables in the context of moderated regression can create spurious product variable effects that are an artifact of curvilinear relations of both predictors to the dependent variable [36]. To foreshadow our results, we did detect curvilinear relations of age and abilities to EPS tests, requiring that moderated regression tests for age $\times$ ability interaction effects include quadratic terms for each predictor variable.

Linear predictor terms were first centered at the sample mean, and then squared predictors were computed to reduce collinearity issues in the multiple regression. Significant moderated regression effects were decomposed by computing simple slopes at the mean and at \pm 1 SD of the predictor variables.

To further understand age differences in the predictive utility of fluid and crystallized abilities for everyday problem solving, we used bootstrapping to examine the regression coefficients for each of the 3 age groups (young, middle-aged, older). Finally, to assess the stability of the observed effects across individual problem solving domains, we examined the contributions of fluid and crystallized abilities for each of the 7 domains in everyday problem solving for young, middle-aged, and older adults.

\section{Results}

\section{Demographic Data and Age-Related Differences}

Demographic data are presented in Table 1, broken down by 3 age groups (young: $24-49$ years old; middle: 50-69 years old; old: 70-93 years old). The 3 age groups differed on years of formal education $(F(2,218)=6.16$, $p=0.002$ ), with young adults having somewhat higher levels than the other 2 age groups. Means and standard deviations of cognitive measures and EPT scores are also presented in Table 1. For descriptive purposes, we presented age effects associated with fluid ability, crystallized ability and everyday problem solving score in scatter plots (Fig. 3). Figure 3a portrays a significant linear age-related decrease in fluid ability $\left(R^{2}=0.626, R_{\text {adjusted }}^{2}=0.625, F(1\right.$, $212)=355.312, p<0.001)$, and the quadratic relationship was also statistically significant $\left(R^{2}=0.64, R_{\text {adjusted }}^{2}=\right.$ $0.637, F(2,211)=187.72, p<0.001)$. In contrast, crystallized ability (Fig. 3b) did not have a significant linear re-

Fig. 3. a Age-related differences in fluid ability. Fluid ability is comprised of the measures on processing speed, working memory, and inductive reasoning. $\mathbf{b}$ Age-related differences in crystallized ability. Crystallized ability is comprised of ETS Advanced Vocabulary Scale, NIHTB-CB Picture Vocabulary, and NIHTB-CB Oral Reading Recognition. c Age-related differences in everyday problem solving. Everyday problem solving is measured by number of correct answers on the Everyday Problems Test (EPT).

Cognitive Predictors of Everyday Problem Solving

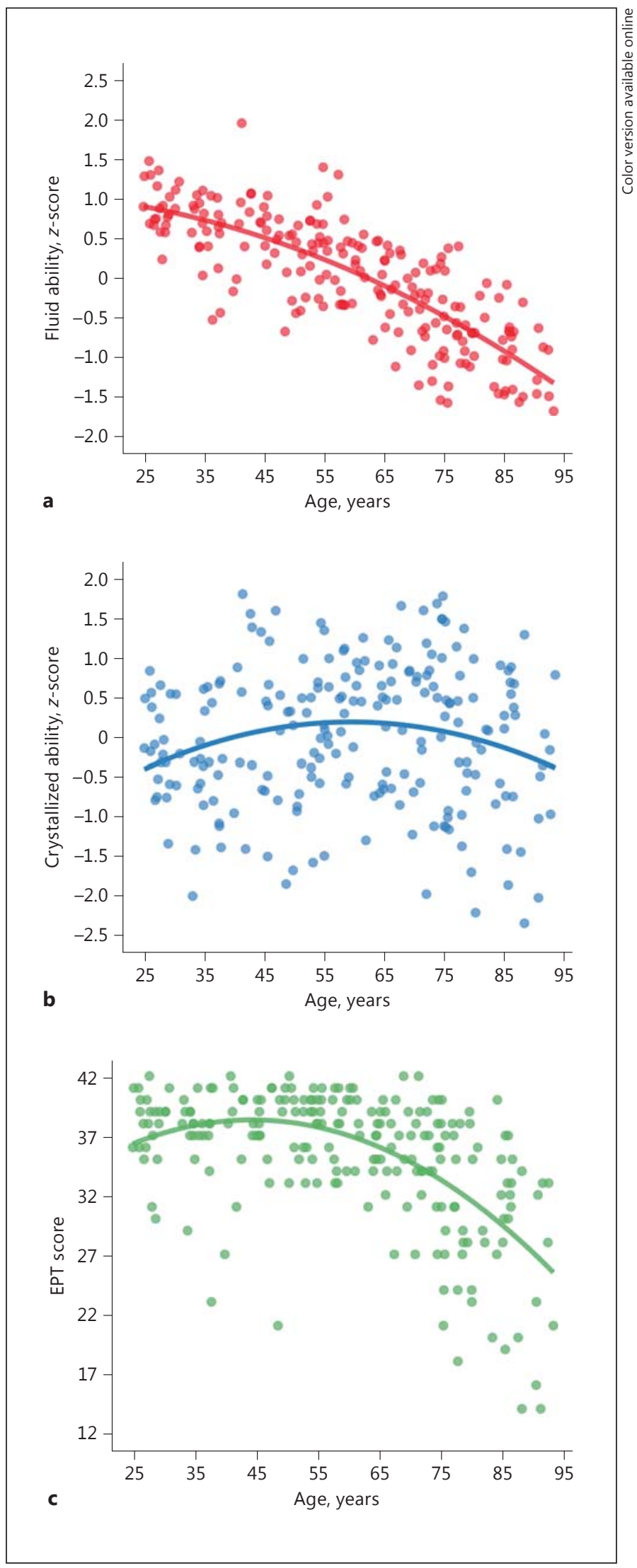

Gerontology 2017;63:372-384

DOI: $10.1159 / 000459622$ 
Table 2. Hierarchical multiple regression

\begin{tabular}{|c|c|c|c|c|c|c|c|c|c|c|}
\hline \multirow[t]{2}{*}{ Coefficient } & \multicolumn{5}{|l|}{ Model 1} & \multicolumn{5}{|l|}{ Model 2} \\
\hline & $b$ & SE & $t$ & $\beta$ & $95 \% \mathrm{CI}$ & $b$ & SE & $t$ & $\beta$ & $95 \% \mathrm{CI}$ \\
\hline Education & 0.399 & 0.135 & $2.969^{* *}$ & 0.169 & $0.134,0.665$ & 0.018 & 0.114 & 0.162 & 0.008 & $-0.206,0.0242$ \\
\hline Age & -0.146 & 0.017 & $-8.51^{* *}$ & -0.491 & $-0.179,-0.112$ & -0.152 & 0.013 & $-11.436^{* *}$ & -0.514 & $-0.179,-0.126$ \\
\hline$\overline{\mathrm{Age}^{2}}$ & -0.005 & 0.001 & $-5.822 * *$ & -0.324 & $-0.007,-0.003$ & -0.003 & 0.001 & $-4.59^{* *}$ & -0.203 & $-0.005,-0.002$ \\
\hline Fluid Ability & & & & & & 1.704 & 0.278 & $6.138^{* *}$ & 0.302 & $1.157,2.251$ \\
\hline Crystallized Ability & & & & & & 1.859 & 0.299 & $6.219^{* *}$ & 0.329 & $1.270,2.448$ \\
\hline \multicolumn{11}{|l|}{ Fluid Ability $^{2}$} \\
\hline \multicolumn{11}{|l|}{ Crystallized Ability $^{2}$} \\
\hline \multicolumn{11}{|l|}{ Age $\times$ Crystallized Ability } \\
\hline \multicolumn{11}{|l|}{ Age $\times$ Fluid Ability } \\
\hline \multicolumn{11}{|l|}{ Crystallized $\times$ Fluid } \\
\hline \multicolumn{11}{|l|}{ Crystallized $\times$ Fluid $\times$ Age } \\
\hline$F$ total & $40.711^{* *}$ & & & & & $68.777^{* *}$ & & & & \\
\hline$\overline{R^{2}}$ & $0.369^{* *}$ & & & & & $0.624^{* *}$ & & & & \\
\hline$\overline{\text { Adjusted } R^{2}}$ & $0.36^{* *}$ & & & & & $0.615^{* *}$ & & & & \\
\hline$\Delta F$ & & & & & & $70.35^{* *}$ & & & & \\
\hline$\overline{\Delta R^{2}}$ & & & & & & $0.255^{* *}$ & & & & \\
\hline \multirow[t]{2}{*}{ Coefficient } & \multicolumn{5}{|l|}{ Model 3} & \multicolumn{5}{|c|}{ Model 4 (full model) } \\
\hline & $b$ & SE & $t$ & $\beta$ & $95 \% \mathrm{CI}$ & $\bar{b}$ & SE & $t$ & $\beta$ & $95 \% \mathrm{CI}$ \\
\hline Education & 0.044 & 0.109 & -0.407 & -0.019 & $-0.17,0.259$ & 0.025 & 0.107 & 0.232 & 0.011 & $-0.186,0.236$ \\
\hline$\overline{\text { Age }}$ & -0.144 & 0.013 & $-11.138^{* *}$ & -0.486 & $-0.17,-0.119$ & -0.143 & 0.014 & $-10.02^{* *}$ & -0.483 & $-0.171,-0.115$ \\
\hline $\mathrm{Age}^{2}$ & -0.004 & 0.001 & $-5.235^{* *}$ & -0.223 & $-0.005,-0.002$ & -0.003 & 0.001 & $-5.013^{* *}$ & -0.211 & $-0.005,-0.002$ \\
\hline Fluid Ability & 1.621 & 0.267 & $6.078^{* *}$ & 0.287 & $1.095,2.146$ & 1.697 & 0.269 & $6.304^{* *}$ & 0.301 & $1.166,2.228$ \\
\hline Crystallized Ability & 1.712 & 0.293 & $5.842^{* *}$ & 0.303 & $1.135,2.290$ & 1.576 & 0.292 & $5.391^{* *}$ & 0.279 & $0.999,2.152$ \\
\hline Fluid Ability ${ }^{2}$ & -0.501 & 0.167 & $-2.997^{* *}$ & -0.126 & $-0.830,-0.171$ & -0.342 & 0.218 & -1.569 & -0.086 & $-0.773,0.088$ \\
\hline Crystallized Ability $^{2}$ & -0.558 & 0.197 & $-2.829^{* *}$ & -0.123 & $-0.946,-0.169$ & -0.334 & 0.236 & -1.414 & -0.073 & $-0.799,0.132$ \\
\hline Age $\times$ Crystallized Ability & & & & & & 0.046 & 0.016 & $2.943^{* *}$ & 0.152 & $0.015,0.076$ \\
\hline Age $\times$ Fluid Ability & & & & & & 0.008 & 0.016 & 0.503 & 0.024 & $-0.023,0.039$ \\
\hline Crystallized $\times$ Fluid & & & & & & -0.324 & 0.346 & -0.936 & -0.06 & $-1.006,0.359$ \\
\hline Crystallized $\times$ Fluid $\times$ Age & & & & & & 0.014 & 0.014 & 1.01 & 0.051 & $-0.013,0.042$ \\
\hline$F$ total & $56.507^{* *}$ & & & & & $39.367^{* *}$ & & & & \\
\hline$\overline{R^{2}}$ & $0.659^{* *}$ & & & & & $0.683^{* *}$ & & & & \\
\hline$\overline{\text { Adjusted } R^{2}}$ & $0.647^{* *}$ & & & & & $0.666^{* *}$ & & & & \\
\hline$\overline{\Delta F}$ & $10.331^{* *}$ & & & & & $3.858^{* *}$ & & & & \\
\hline$\overline{\Delta R^{2}}$ & $0.034^{* *}$ & & & & & $0.024^{* *}$ & & & & \\
\hline
\end{tabular}

lationship with age ( $p=0.628)$. However, there was a significant quadratic relationship between crystallized ability and age $\left(R^{2}=0.038, R_{\text {adjusted }}^{2}=0.029, F(2,217)=4.258\right.$, $p=0.015)$, with increasing performance until about age 59 . We also examined both linear and quadratic relationships between everyday problem solving ability and age. While the simple linear relationship showed significance $\left(R^{2}=0.237, R_{\text {adjusted }}=0.234, F(1,219)=68.091, p<\right.$ $0.001)$, adding age ${ }^{2}$ significantly improved the model $\left(\Delta R^{2}=0.105, \Delta F=34.810, p<0.001\right)$, suggesting a quadratic relation with age was a better fit for everyday problem solving ability (Fig. $3 \mathrm{c})\left(R^{2}=0.342, R_{\text {adjusted }}^{2}=0.336\right.$,
$F(2,218)=56.707, p<0.001)$, with the peak performance at 47.2 years of age.

\section{Cognitive Predictors across the Lifespan}

We used hierarchical multiple regression to examine the role that fluid and crystallized abilities play in solving everyday problems. In the first model, we included years of education and linear and quadratic components for age. Then in the second model, we added fluid ability and crystallized ability as cognitive predictors. In the third model, we included quadratic components (crystallized ${ }^{2}$ and flu$\left.\mathrm{id}^{2}\right)$ to examine if there was a curvilinear relationship be- 


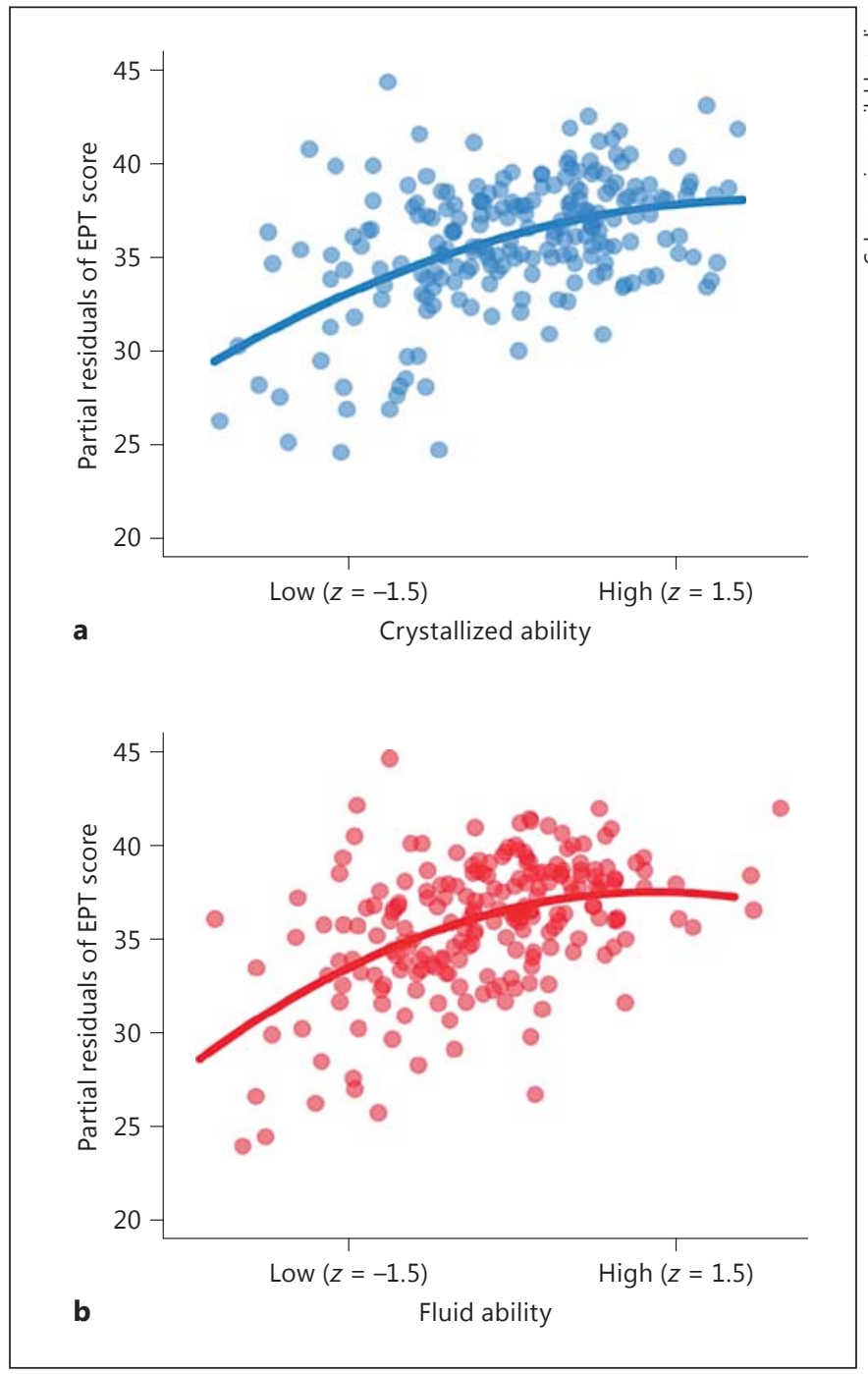

Fig. 4. a Partial residual plot of crystallized ability. b Partial residual plot of fluid ability. For both cognitive predictors, the effect of crystallized and fluid ability follows a similar curvilinear pattern regardless of age and the other cognitive level: for people who have lower cognitive ability, the level of cognitive ability has a strong effect on everyday problem solving, while for people who have high cognitive ability, higher cognitive ability does not affect everyday problem solving as much.

tween cognitive predictors and everyday problem solving. In the fourth model, we added interactions among fluid ability, crystallized ability and age. Each of the aforementioned steps improved the fit of the overall model significantly (Table 2). We also examined a further model that included interactions between cognitive ability and age ${ }^{2}$, and found that it did not improve the model significantly. Therefore, the fourth model was chosen as the final mod-

Cognitive Predictors of Everyday Problem Solving

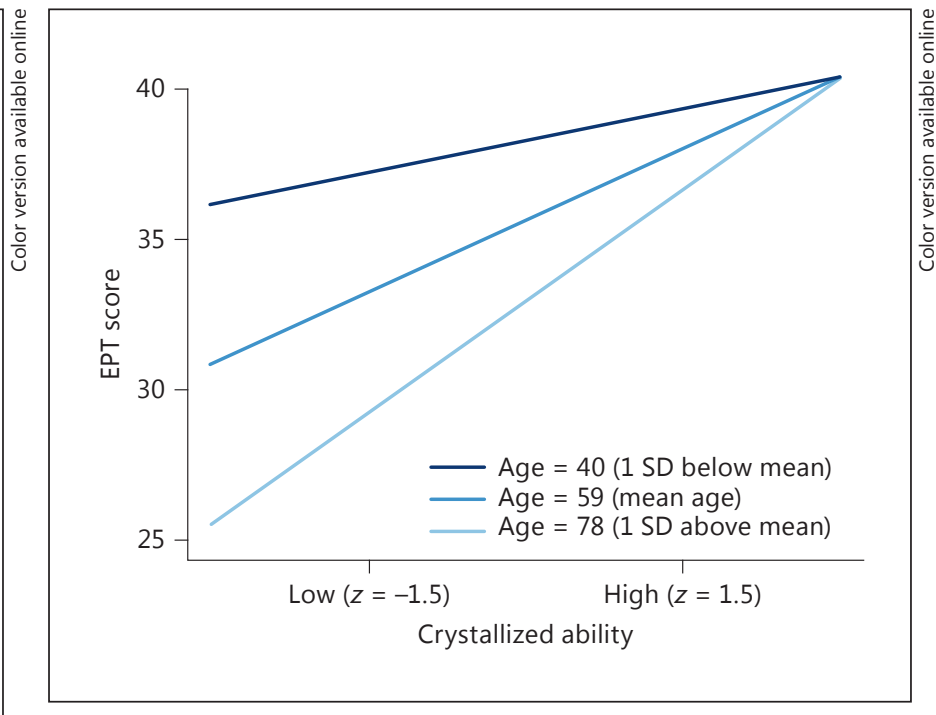

Fig. 5. Simple slopes of Age $\times$ Crystallized ability. Simple slope was not significantly different from 0 at age $=40$ (1 SD below mean), but was significant at age $=59$ (mean age) and age $=78$ ( 1 SD above mean). Based on a comparison using $z$-tests, the effect of crystallized ability was stronger at older age $(z=-3.027, p=0.001)$ and middle age $(z=-1.719, p=0.043)$ than at a younger age, and the effect was even stronger at an older age than middle age $(z=-1.753$, $p=0.04)$. EPT, Everyday Problems Test.

el depicting the relationship between cognitive predictors and everyday problem solving across the lifespan.

As shown in Table 2, model 4 explained a substantial amount of variance in everyday problem solving $\left(R^{2}=\right.$ $0.683, R_{\text {adjusted }}^{2}=0.666$ ). There was a main effect of age, age $^{2}$, fluid ability, and crystallized ability on everyday problem solving. Although the quadratic terms of fluid ability and crystallized ability were not each statistically significant in the final model, adding quadratic terms of these predictors significantly improved the fit of the model. The partial residual plots of crystallized ability (Fig. 4a) and fluid ability (Fig. $4 \mathrm{~b}$ ) showed that these 2 predictors both evidenced a similar curvilinear pattern to everyday problem solving. Curvilinearity occurred because for lower-ability participants compared to those of higher ability, cognitive ability had a stronger relationship to everyday problem solving.

Critically, we also found a significant Age $\times$ Crystallized ability interaction $(b=0.046, S E b=0.016, t(201)=$ 2.943, $\beta=0.152, p=0.004,95 \%$ confidence interval $[\mathrm{CI}]=0.015,0.076)$, indicating the relationship between crystallized ability and everyday problem solving differed across the lifespan. In order to better interpret the significant interaction, simple slopes (displayed in Fig. 5) for 
Table 3. Regression coefficient estimates and $95 \% \mathrm{BCa}$ CI in 3 age groups

\begin{tabular}{|c|c|c|c|c|c|c|c|c|c|}
\hline & \multicolumn{3}{|l|}{ Young } & \multicolumn{3}{|l|}{ Middle } & \multicolumn{3}{|l|}{ Older } \\
\hline & $95 \% \mathrm{BCa} C \mathrm{CI}$ & $b$ & $\beta$ & $95 \% \mathrm{BCa} C I$ & $b$ & $\beta$ & $95 \% \mathrm{BCa} C I$ & $b$ & $\beta$ \\
\hline Age & $-0.168,0.169$ & -0.022 & -0.042 & $-0.255,-0.07$ & $-0.153^{* *}$ & -0.297 & $-0.475,-0.065$ & $-0.302^{* *}$ & -0.306 \\
\hline Fluid & $0.396,2.467$ & $1.703^{*}$ & 0.395 & $0.646,2.374$ & $1.364^{* *}$ & 0.426 & $0.454,2.661$ & $1.605^{* *}$ & 0.265 \\
\hline Fluid $^{2}$ & $-1.627,0.688$ & -0.03 & -0.012 & $-1.394,0.21$ & -0.362 & -0.146 & $-1.38,0.32$ & -0.675 & -0.135 \\
\hline Crystallized & $-0.273,2.745$ & 0.976 & 0.229 & $0.18,1.528$ & $0.921^{*}$ & 0.256 & $1.662,4.116$ & $2.753^{* *}$ & 0.502 \\
\hline Crystallized $^{2}$ & $-1.44,0.854$ & -0.276 & -0.079 & $-1.005,1.061$ & -0.237 & -0.063 & $-1.471,0.184$ & -0.714 & -0.173 \\
\hline Crystallized Fluid & $-3.621,2.059$ & -0.867 & -0.244 & $-1.644,1.36$ & -0.209 & -0.055 & $-0.966,1.725$ & 0.511 & 0.084 \\
\hline
\end{tabular}

the relationship between crystallized ability and everyday problem solving were tested for younger age ( -1 SD below the mean), middle age (mean), and older age ( $+1 \mathrm{SD}$ above the mean). Simple slope tests showed that the relationship of crystallized ability to everyday problem solving at a younger age was not significant $(b=0.708, S E b=$ $0.433, t(201)=1.636, \beta=0.125, p=0.103,95 \% \mathrm{CI}=$ $-0.146,1.562)$. However, both the middle age model $(b=$ $1.576, S E b=0.292, t(201)=5.391, \beta=0.279, p<0.001$, $95 \% \mathrm{CI}=0.999,2.152)$ and the older age model $(b=2.44$, $S E b=0.397, t(201)=6.141, \beta=0.432, p<0.001,95 \%$ $\mathrm{CI}=1.656,3.223)$ revealed a significant positive association between crystallized ability and everyday problem solving. We then tested the difference between regression coefficients across models, and found that the effect of crystallized ability was stronger for both old $(z=-3.027$, $p=0.001)$ and middle age $(z=-1.719, p=0.043)$ compared to young, and that the effect was even stronger for the old age compared to middle age $(z=-1.753, p=0.04)$, suggesting that crystallized ability played a continuously increasingly important role in solving everyday problems as age increased. Note that the interaction between fluid and crystallized ability was not significant $(p=0.351)$, suggesting that the contribution of crystallized ability did not change across people with different fluid ability, after taking age-related effects into account.

\section{Comparing Cognitive Predictors in Three Age Groups}

To further examine which cognitive predictor - fluid or crystallized ability - was more important for everyday problem solving at different stages of the lifespan, we generated bootstrapped standard errors for regression coefficients in 3 age subgroups: younger adults (24-49 years old), middle-aged adults (50-69 years old), and older adults (70-93 years old). In each multiple regression, the

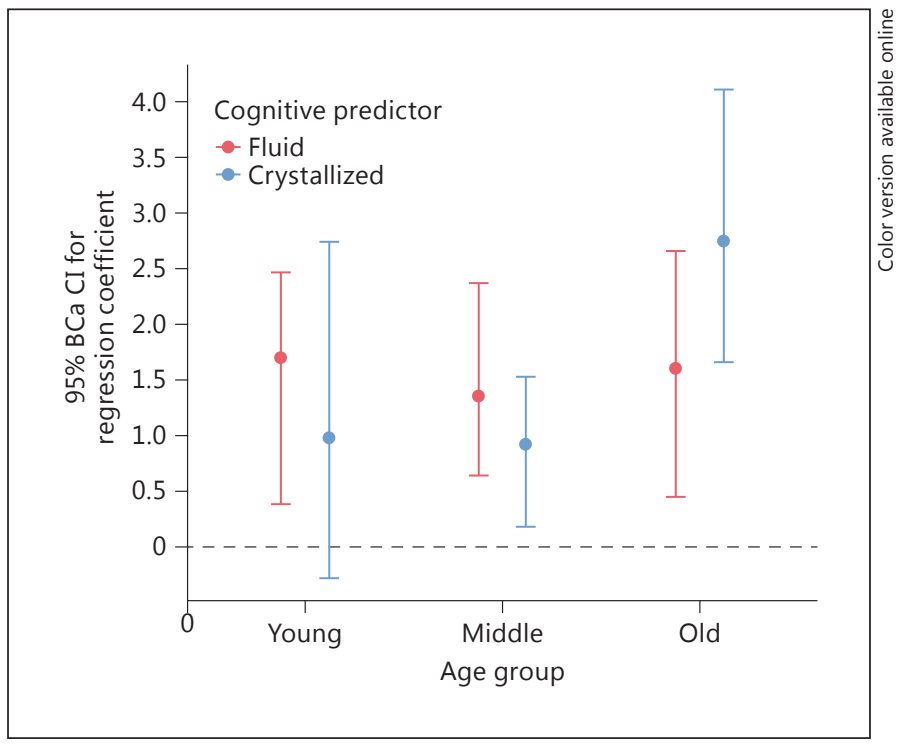

Fig. 6. 95\% BCa CI for fluid and crystallized regression coefficients. In older adults, everyday problem solving was predicted more by crystallized ability than fluid ability, proportion overlap $=42.8 \%$, $p<0.05$.

predictor variables were age, fluid ability, crystallized ability, fluid ${ }^{2}$, crystallized ${ }^{2}$, and the Fluid $\times$ Crystallized interaction. This model was derived from model 4 used for the whole sample with first-order age-related effects removed since this analysis was on each age group. We generated 95\% CI using bias-corrected and accelerated (BCa) bootstrap (with 1,000 iterations in each group) as presented in Table 3. We then compared the BCa CI using a conservative rule by examining the overlap of $\mathrm{CI}$ [37]. Put simply, the rule assesses whether the 95\% CI have less than $50 \%$ proportion overlap, expressed as a proportion of average margin of error. If the result is af- 
Table 4. Regression coefficient estimates and 95\% BCa CI for 7 EPT domains

\begin{tabular}{|c|c|c|c|c|c|c|}
\hline \multirow[t]{2}{*}{ EPT domain } & \multicolumn{3}{|l|}{ Fluid } & \multicolumn{3}{|l|}{ Crystallized } \\
\hline & $95 \%$ BCa CI & $b$ & $\beta$ & $95 \%$ BCa CI & $b$ & $\beta$ \\
\hline \multicolumn{7}{|l|}{ Young } \\
\hline Shopping & $-0.096,0.388$ & 0.143 & 0.178 & $0.029,0.498$ & 0.23 & 0.289 \\
\hline Finance & $0.084,0.576$ & $0.344^{* *}$ & 0.406 & $-0.134,0.297$ & 0.057 & 0.067 \\
\hline Household & $-0.015,0.588$ & $0.292^{*}$ & 0.328 & $-0.218,0.318$ & 0.037 & 0.042 \\
\hline Meal & $-0.206,0.521$ & 0.263 & 0.249 & $-0.010,0.562$ & 0.25 & 0.239 \\
\hline Medication & $-0.233,0.238$ & 0.075 & 0.104 & $-0.047,0.406$ & 0.163 & 0.228 \\
\hline Phone & $-0.267,0.390$ & 0.1 & 0.094 & $-0.029,0.584$ & 0.238 & 0.227 \\
\hline Transportation & $0.018,0.672$ & $0.385^{*}$ & 0.379 & $-0.206,0.318$ & 0.032 & 0.032 \\
\hline \multicolumn{7}{|l|}{ Middle-aged } \\
\hline Shopping & $-0.073,0.308$ & 0.075 & 0.087 & $0.110,0.541$ & $0.325^{* *}$ & 0.337 \\
\hline Finance & $-0.026,0.327$ & $0.174^{*}$ & 0.248 & $-0.059,0.366$ & 0.156 & 0.198 \\
\hline Household & $-0.045,0.356$ & 0.142 & 0.186 & $-0.274,0.180$ & -0.036 & -0.042 \\
\hline Meal & $0.002,0.357$ & 0.168 & 0.212 & $-0.028,0.348$ & 0.162 & 0.183 \\
\hline Medication & $0.026,0.393$ & $0.195^{*}$ & 0.271 & $-0.092,0.319$ & 0.12 & 0.148 \\
\hline Phone & $0.077,0.762$ & 0.337 & 0.296 & $-0.094,0.544$ & 0.243 & 0.190 \\
\hline Transportation & $0.052,0.519$ & $0.265^{*}$ & 0.343 & $-0.327,0.188$ & -0.046 & -0.053 \\
\hline \multicolumn{7}{|l|}{ Older } \\
\hline Shopping & $0.006,0.482$ & $0.253^{*}$ & 0.236 & $0.127,0.582$ & $0.345^{* *}$ & 0.356 \\
\hline Finance & $0.071,0.529$ & $0.298^{*}$ & 0.284 & $0.119,0.580$ & $0.345^{* *}$ & 0.363 \\
\hline Household & $-0.166,0.449$ & 0.157 & 0.122 & $0.042,0.694$ & $0.353^{*}$ & 0.304 \\
\hline Meal & $0.049,0.698$ & $0.408^{*}$ & 0.306 & $-0.001,0.633$ & 0.293 & 0.242 \\
\hline Medication & $-0.040,0.428$ & 0.18 & 0.192 & $0.098,0.540$ & $0.308^{* *}$ & 0.363 \\
\hline Phone & $-0.068,0.574$ & 0.259 & 0.189 & $0.100,0.773$ & $0.450^{* *}$ & 0.362 \\
\hline Transportation & $-0.028,0.461$ & 0.24 & 0.182 & $0.305,0.792$ & $0.528^{* *}$ & 0.443 \\
\hline
\end{tabular}

firmative, the 2 estimates are significantly different $(p<$ $0.05)$. As shown in Figure 6, for the young group, the lower end of $95 \% \mathrm{CI}$ of the crystallized ability parameter was below zero, confirming its nonsignificance and that only the fluid ability value was predictive, as we found in simple slope analysis. For the middle age, the $95 \%$ CIs of fluid and crystallized abilities overlapped more than 50\%, suggesting that both were predictive but not significantly different in middle-aged adults. Finally, for the older group, the predictive utility of crystallized ability was significantly larger than fluid ability, with the proportion overlap $=42.8 \%, p<0.05$. Hence, in middle-aged and older adults, everyday problem solving was associated with both fluid and crystallized abilities. Importantly for older adults, crystallized ability was a significantly stronger predictor compared to fluid ability (Fig. 6).

We also note that we found no evidence for a Fluid $x$ Crystallized interaction within any age group. The ab- sence of the interaction suggests that fluid and crystallized ability made independent contributions to everyday problem solving, regardless of level of performance on either ability.

In a final analysis, we assessed the stability of the effects of fluid and crystallized ability for each of the 7 problemsolving domains within each age group using the same bootstrapping approach. The main finding was that for older adults, crystallized ability played an important role for all EPT domains except meal preparation, which was marginally significant. In addition, fluid ability was significant for shopping, finance, and meal preparation in older adults (Table 4). Table 4 also shows that for young adults, fluid ability was significant for finance, household and transportation, and for finance, medication and transportation in middle-aged adults. Crystallized ability played no significant role for young adults, and significantly predicted only shopping in middle age. 


\section{Discussion}

The main goal of this study was to understand how fluid and crystallized ability differ across the lifespan in predicting everyday problem solving. We hypothesized that due to diminished fluid resources with age, crystallized knowledge would become increasingly important in predicting everyday problem solving as a function of age. Congruent with this hypothesis, crystallized ability (measured by verbal knowledge in this study) played a more important role in predicting everyday problem solving as age increased. In contrast, fluid ability (measured by speed, working memory, and inductive reasoning) consistently explained variance for all age groups. This pattern of findings suggests that older adults are relying more on crystallized knowledge to solve everyday problems, whereas young adults rely more heavily on the efficiency of basic cognitive mechanisms (e.g., processing speed, working memory, inductive reasoning) that comprise fluid ability.

Past studies have been inconclusive about the relative roles of crystallized versus fluid abilities in everyday problem solving at different ages because none that have examined this issue have included a lifespan sample. The inclusion of the entire adult lifespan was an important feature of the present study, as it allowed us to begin to clarify when in the lifespan crystallized knowledge assumes importance in everyday problem solving. We began to observe a small contribution of crystallized ability to everyday problem solving in middle age, with a large contribution at older ages. The present findings provide clear evidence for the importance of including middleaged samples in studies.

We also note that the present findings replicate a pattern reported by Hedden et al. [26] for a very different task - a verbal cued recall task that required participants to memorize associations between paired cues and target words. Hedden et al. [26] used crystallized and fluid ability to predict performance on the verbal recall task. Just as reported in the present study, they found that crystallized ability (vocabulary scores) explained more variance for older compared to middle-aged and young adults. The similarity of the findings for these 2 very different tasks suggests that increasing reliance on crystallized ability may be a general characteristic of aging. Buttressing this conclusion was the finding that crystallized ability accounted for significant variance in older adults in 6 of the 7 EPT domains, suggesting that the breadth of the effect was reliable across domains. Moreover, the crystallized ability effect was nearly absent in the young and middle- aged adults, with only 1 significant effect for shopping in the middle-aged.

The notion that age differentially affects the type of cognitive ability drawn upon to perform everyday cognitive tasks has not received much attention in the literature. The present findings suggest that crystallized knowledge may help older adults maintain cognitive function in the face of declining fluid ability. Other studies of problem-solving support this interpretation. For example, older adults actually showed better problem-solving abilities than young and middle-aged adults when they were presented with problems associated with social conflict and interpersonal conflict. The solution to these types of problems rely more on wisdom and a broad range of social experiences rather than fluid ability [38]. Similarly, there is evidence that older adults develop adaptive, experience-based heuristics for solving everyday problems and make decisions that minimize the need to rely on fluid reasoning [39]. Conversely, there are also domains where crystallized ability makes a scant contribution, even for older adults. We suggest that these would be domains that require extensive on-line processing, such as constantly switching and updating information of different ingredients and procedures when cooking.

It is also important to recognize that everyday problem solving ability is a crucial skill that greatly affects older adults' life quality, but few studies have examined the predictive utility of respondent-based, laboratory problem solving tasks (such as the EPT) in the real world. In support of the use of such laboratory measures, there is a small body of evidence suggesting that the EPT explains substantial variance in every day functioning $[16,34,40]$; but much more research is needed. Moreover, the EPT consists of sets of questions that address well-defined, but relatively narrow everyday problems. Real-world problems are typically more complex, are more open-ended (ill-defined), and are comprised of many smaller interrelated problems that require different aspects of knowledge, skills, and abilities. Thus, the EPT may not adequately mirror the complexity of real world problems. Additional investigation of ability predictors of everyday problem solving tasks would help to address this concern.

A limitation of this study is that crystallized ability was measured by vocabulary tasks, which have been traditionally considered as a proxy of knowledge and experience in cognitive psychology studies and everyday problem solving research. However, we acknowledge that a broader assessment of crystallized ability would incorporate experience and other types of world knowledge. Future research with more comprehensive assessment of
382

Gerontology 2017;63:372-384

DOI: $10.1159 / 000459622$
Chen/Hertzog/Park 
knowledge and experience beyond measures of vocabulary may help to understand the individual differences in people's utilization of cognition in solving everyday problems. One option might be to assess expertise and familiarity participants have in each problem solving domain in an effort to understand how life experiences asset problem solving. Similar strategies could be adapted to different problem solving paradigms.

We also recognize that it would be ideal to have longitudinal data on both cognitive and everyday problem solving so that the changing relationship between cognitive measures and everyday performance could be assessed as people grow and age. Cross-sectional designs are vulnerable to cohort differences and age $\times$ selection confounds. Finally, the compensatory role of crystallized ability may be maximized in high-functioning samples of older adults. Participants in this study were well educated ( mean years of education $=16.6)$; individuals with lower levels of educational attainment may not show the same degree of compensatory benefit (although we found no evidence of Fluid $\times$ Crystallized interactions in predicting EPS performance). It would therefore be useful to evaluate these relationships in a more representative sample of the population that included low-education individuals.

In conclusion, the present study suggests that young adults may solve everyday problems based on cognitive resources and mechanisms that are traditionally associated with effective problem solving. However, crystallized knowledge becomes a more predominant influence on everyday problem solving in older adults.

\section{Acknowledgements}

This work was supported by National Institute on Aging at the National Institutes of Health (grant number 5R37AG006265-29 to D.C.P.).

\section{References}

1 Willis SL: Everyday cognitive competence in elderly persons: conceptual issues and empirical findings. Gerontologist 1996;36:595-601.

2 Diehl M: in Everyday competence later life: current status and future directions. Gerontologist 1998;38:422-433.

3 Denney NW, Pearce KA: A developmental study of practical problem solving in adults. Psychology Aging 1989;4:438-442.

4 Thornton WL, Paterson TSE, Yeung SE: Age differences in everyday problem solving: the role of problem context. Int J Behav Dev 2013; 37:13-20.

5 Heidrich SM, Denney NW: Does social problem solving differ from other types of problem solving during the adult years? Exp Aging Res 1994;20:105-126.

6 Kimbler KJ: Everyday problem solving and instrumental activities of daily living: support for domain specificity. Behav Sci (Basel) 2013; 3:170-191.

7 Tucker-Drob EM: Neurocognitive functions and everyday functions change together in old age. Neuropsychology 2011;25:368-377.

8 Ackerman PL: A theory of adult intellectual development: process, personality, interests, and knowledge. Intelligence 1996;22:227257.

9 Park DC, Lautenschlager G, Hedden T, Davidson NS, Smith AD, Smith PK: Models of visuospatial and verbal memory across the adult life span. Psychology Aging 2002;17: 299-320.
10 Schaie KW, Willis SL, Caskie GI: The Seattle Longitudinal Study: relationship between personality and cognition. Neuropsychol Dev Cogn B Aging Neuropsychol Cogn 2004;11: 304-324.

11 Craik FI, Jennings JM: Human memory; in Craik FI, Salthouse T (eds): The Handbook of Aging and Cognition. Hillsdale, Lawrence Erlbaum Associates, 1992, pp 51-110.

12 Kane MJ, Hambrick DZ, Conway AR: Working memory capacity and fluid intelligence are strongly related constructs: comment on Ackerman, Beier, and Boyle (2005). Psychol Bull 2005;131:66-71; author reply 72-65.

13 Allaire JC, Marsiske M: Everyday cognition: age and intellectual ability correlates. Psychology Aging 1999;14:627-644.

14 Diehl M, Willis SL, Schaie KW: Everyday problem solving in older adults: observational assessment and cognitive correlates. Psychology Aging 1995;10:478-491.

15 Gross AL, Rebok GW, Unverzagt FW, Willis SL, Brandt J: Cognitive predictors of everyday functioning in older adults: results from the active cognitive intervention trial. J Gerontol B Psychol Sci Soc Sci 2011;66:557-566.

16 Marsiske M, Margrett JA: Everyday problem solving and decision making; in Birren JE, Schaie KW, Abeles RP, Gatz M, Salthouse TA (eds): Handbook of the Psychology of Aging. Amsterdam, Elsevier, 2006, pp 315-342.

17 Park DC, Hertzog C, Leventhal H, Morrell RW, Leventhal E, Birchmore D, Martin M, Bennett J: Medication adherence in rheumatoid arthritis patients: older is wiser. J Am Geriatr Soc 1999;47:172-183.
18 Willis SL, Tennstedt SL, Marsiske M, Ball K, Elias J, Koepke KM, Morris JN, Rebok GW, Unverzagt FW, Stoddard AM, Wright E, Group AS: Long-term effects of cognitive training on everyday functional outcomes in older adults. JAMA 2006;296:2805-2814.

19 Kirasic KC, Allen GL, Dobson SH, Binder KS: Aging, cognitive resources, and declarative learning. Psychology Aging 1996;11:658-670.

20 Burton CL, Strauss E, Hultsch DF, Hunter MA: Cognitive functioning and everyday problem solving in older adults. Clin Neuropsychol 2006;20:432-452.

21 Rebok GW, Ball K, Guey LT, Jones RN, Kim HY, King JW, Marsiske M, Morris JN, Tennstedt SL, Unverzagt FW, Willis SL; ACTIVE Study Group: Ten-year effects of the advanced cognitive training for independent and vital elderly cognitive training trial on cognition and everyday functioning in older adults. J Am Geriatr Soc 2014;62:16-24.

22 Cornelius SW, Caspi A: Everyday problem solving in adulthood and old age. Psychol Aging 1987;2:144-153.

23 Thornton WL, Deria S, Gelb S, Shapiro RJ, Hill A: Neuropsychological mediators of the links among age, chronic illness, and everyday problem solving. Psychol Aging 2007;22:470481.

24 Park DC: Psychological Issues Related to Competence: Cognitive Aging and Instrumental Activities of Daily Living; Social Structures and Aging. Mahwah, Lawrence Erlbaum Associates, 1997, pp 66-82.
Cognitive Predictors of Everyday Problem Solving
Gerontology 2017;63:372-384 DOI: $10.1159 / 000459622$ 
25 Baltes PB, Staudinger UM, Lindenberger U: Lifespan psychology: theory and application to intellectual functioning. Annu Rev Psychol 1999;50:471-507.

26 Hedden T, Lautenschlager G, Park DC: Contributions of processing ability and knowledge to verbal memory tasks across the adult life-span. Q J Exp Psychol A 2005;58:169-190.

27 Willis SL, Marsiske M: Manual for the Everyday Problems Test. University Park, Pennsylvania State University, 1993, pp 1-31.

28 Salthouse TA, Babcock RL: Decomposing adult age differences in working memory. Dev Psychol 1991;27:14.

29 Wechsler D: WAIS-III, Wechsler Adult Intelligence Scale: Administration and Scoring Manual. San Antonio, The Psychological Corporation, 1997.

30 Casaletto KB, Umlauf A, Beaumont J, Gershon R, Slotkin J, Akshoomoff N, Heaton RK: Demographically corrected normative standards for the English version of the NIH toolbox cognition battery. J Int Neuropsychol Soc 2015;21:378-391.
31 Robbins TW, James M, Owen AM, Sahakian BJ, McInnes L, Rabbitt P: Cambridge Neuropsychological Test Automated Battery (CANTAB): a factor analytic study of a large sample of normal elderly volunteers. Dementia 1994; 5:266-281.

32 Ekstrom RB, French JW, Harman HH, Dermen D: Manual for Kit of Factor Referenced Cognitive Tests. Princeton, Educational Testing Service 1976.

33 Raven J, Raven JC, Court JH: Manual for Raven's Progressive Matrices and Vocabulary Scale. San Antonio, The Psychological Corporation, 1998.

34 Schmitter-Edgecombe M, Parsey C, Cook DJ: Cognitive correlates of functional performance in older adults: comparison of self-report, direct observation, and performancebased measures. J Int Neuropsychol Soc 2011; 17:853-864.
35 Hertzog C: Influences of cognitive slowing on age differences in intelligence. Dev Psychol 1989;25:16.

36 Lubinski D, Humphreys LG: Assessing spurious "moderator effects": illustrated substantively with the hypothesized ("synergistic") relation between spatial and mathematical ability. Psychol Bull 1990;107:385-393.

37 Cumming G: Inference by eye: reading the overlap of independent confidence intervals. Stat Med 2009;28:205-220.

38 Grossmann I, Na J, Varnum ME, Park DC, Kitayama S, Nisbett RE: Reasoning about social conflicts improves into old age. Proc Natl Acad Sci USA 2010;107:7246-7250.

39 Mata R, Schooler LJ, Rieskamp J: The aging decision maker: cognitive aging and the adaptive selection of decision strategies. Psychology Aging 2007;22:796-810.

40 Allaire JC, Marsiske M: Well- and ill-defined measures of everyday cognition: relationship to older adults' intellectual ability and functional status. Psychol Aging 2002;17:101115 . 